\title{
Violência doméstica contra o homem: de agressor a agredido
}

\author{
Flávia Saletti Grecco DOTOLI ${ }^{1}$ \\ Andreza Marques de Castro LEÃO²
}

\section{Introdução e justificativa}

A violência Doméstica é um problema de natureza social que vem afetando centenas de mulheres em todo mundo. É uma amostra que traz como conceito a violência de gênero atingindo mulheres de todas as faixas etárias e de diferentes classes sociais, regiôes, grupos étnico-raciais, graus de escolaridade, orientação do desejo sexual e religião (CÔRTES, 2012).

$\mathrm{Na}$ tentativa de atender as demandas advindas de agressão contra as mulheres alguns órgãos foram implantados quais sejam: SOS, Delegacias Especializadas de atendimento à mulher, casas de abrigo, legislaçóes específicas, centros de referência da mulher, dentre outros. Estes instrumentos surgiram a partir das manifestaçôes públicas, pesquisas centralizadas na compreensão da dinâmica das relaçóes de violência, assim como, lutas travadas pelo movimento de mulheres e feministas na ocasião em que questionavam a situação social das mulheres, resultando em inúmeras conquistas (CÔRTES, 2012).

1 Mestranda em Educação Sexual. UNESP - Universidade Estadual Paulista. Faculdade de Ciências e Letras. Araraquara - SP - Brasil. 14800-901-fgdotoli@ yahoo.com.br

2 UNESP - Universidade Estadual Paulista. Faculdade de Ciências e Letras Departamento de Psicologia da Educação - Pós-graduação em Educação Sexual. Araraquara - SP - Brasil. 14800-901 - andrezaleao@fclar.unesp.br 
No Brasil a resistência feminista contra a violência sofrida pelas mulheres ocasionou transformaçóes históricas nos processos no âmbito legislatório, institucionais e legais. Tais transformaçôes se iniciaram no período da ditadura militar, sobretudo, na década de 1970, quando no panorama das demandas pela anistia política de centenas de homens e mulheres vítimas da violência militar, segmentos do movimento feminista brasileiro se compeliram em delatar a violência cometida contra as mulheres no próprio lar. Esta ação de resistência se fortaleceu com várias estratégias de luta, dentre elas, a nominação da expressáo "violência contra a mulher", seguida pela demanda por políticas públicas a fim de coibi-la. (BANDEIRA, 2009). Segundo Côrtes (2012, p.150) o

[...] movimento feminista e o movimento de mulheres configuraram-se como protagonistas mais contundentes da politização da violência doméstica no Brasil, na década de 1970, na medida em que transgrediram dicotomias e fronteiras, inserindo, no espaço público, o debate e a denúncia referentes àquela modalidade de crime considerada estanque do espaço político, alheia à responsabilidade do Estado. Justamente por acometer mulheres no espaço intrafamiliar, em relaçôes afetivas, a violência doméstica não é postulada como problema estrutural, ou como uma violação dos direitos humanos, assim como outras formas de violências que ocorrem nas ruas, perpetradas por estranhos.

No que concerne à implantação de conselhos da condição feminina e as Delegacias da mulher, Blay (2003) discorre que mediante anistia ocorrida em 1979, bem como, a eleiçấo direta de governadores em 1982, concomitantemente com a reorganização partidária, o universo feminista iniciou um período de fortalecimento, contudo, se segmentou em grupos partidários.

Em 1983 foi criado o primeiro Conselho Estadual da Condição feminina na cidade de São Paulo para fazer frente às demandas de igualdade de gênero, órgão este voltado de modo eminente para a repressão da violência contra a mulher, tonificando vários grupos feministas de apoio a essas mulheres, um trabalho voluntarioso e com escassos recursos (BLAY, 2003).

Outrossim afirmou Blay, (2003) que em anos anteriores a criação do Conselho Estadual, as mulheres recorriam as Delegacias em geral, visto que sentiam-se ameaçadas ou vítimas de incompreensão, machismo e violência sexual. A partir da criaçáo das delegacias de Defesa da mulher (DDM) todo o quadro passou a ser alterado, isto é, o serviço nas Delegacias era prestado e ainda é por mulheres, mas este modelo não bastava apenas, visto que muitas das profissionais foram socializadas numa cultura machista e agiam de acordo com tais padróes. Observou necessidade expressiva em realizar treinamentos e conscientizaçóes para a capacitaçáo destas e novos profissionais, sobretudo no entendimento de 
que meninas e mulheres tinham o direito de não aceitara violência cometida por pais, padrastos, maridos, companheiros e outros.

A tarefa de reciclar os profissionais deverá passar pelo crivo da educação permanente, pois os quadros funcionais e problemas alteram as intervençóes diante da mulher agredida em busca de acolhimento. Decompor essa relaçáo de subordinação de gênero foi o início de uma revolução parcialmente bemsucedida nos papéis sociais, embora os crimes de gênero tenha continuado. Estudos identificaram que os crimes não incidiam apenas dos maridos, mas outros parceiros também agrediam e matavam as mulheres sob os mais diversos ensejos (BLAY, 2003).

Nesta acepção, na área estratégia no 4 inserida no V Plano Nacional contra Violência Doméstica e de Gênero (BRASIL, 2013, p.7025)

A qualificação permanente de profissionais, que intervêm na prevenção e combate à violência de gênero e à violência doméstica, tem sido essencial, promovendo uma atuaçáo mais adequada às exigências e conduzindo a que as vítimas confiem cada vez mais no sistema de apoio existente, sendo fundamental para revelar a violência que ainda se encontra invisível. Uma melhor capacitação de profissionais nesta área também contribui para a diminuição da vitimação secundária e da revitimação. No que se refere às forças de segurança, pretende -se intensificar o esforço considerável já realizado nos últimos anos, através da concepçáo e aprovação de um plano de formação para a PSP e GNR que abranja todas as esquadras e postos. Esta área estratégica inclui 7 medidas centradas na qualificação técnica e pessoal de profissionais de diversas áreas de atuação, que trabalham, direta ou indiretamente, com as vítimas de violência doméstica e de género e respetivos(as) agressores(as). Constituem seus objetivos estratégicos: 1) Intensificar a formação de profissionais; 2) Criar e implementar referenciais de formação orientados para a intervenção com públicos particularmente vulneráveis.

De acordo com Bandeira (2009, p.403) em meados de 2000

[...] a intensificação da luta pela democratizaçáo dos direitos humanos e pela cidadania impulsionou a criação da Secretaria Especial de Políticas para Mulheres, que se efetivou em 2003, e esteve presente na elaboração da nova legislação destinada a erradicar a violência contra as mulheres, fenômeno que ainda hoje se expressa em dados alarmantes.

Ante isto, compreende-se que o processo de luta neste movimento se ultimava para a extinção da opressão (dominação exploração) das mulheres, estando além de colocá-las em situação de equidade com os homens. Objetivando 
o estabelecimento das relaçóes sociais inclinadas na equidade substantiva. Assim, a interlocução entre algumas vertentes deste movimento tem sido fecundo com sujeitos coletivos que atuam na organização da classe trabalhadora, quais sejam: sindicatos, partidos políticos, movimentos sociais e outros sujeitos coletivos (SANTOS; OLIVEIRA, 2010). Não obstante, nota-se que a mulher buscou legitimar seus direitos e, acima disso, firmou este conceito através da legitimação jurisprudencial.

Em sentido contrário, conforme aponta Bandeira (2009, p.405)

[...] a performance masculina tem resistido aos processos de mudança, tentando preservar os modelos culturais e cognitivos que lhes garantem o status quo, as assimetrias em relação ao exercício do poder estabelecido no grupo, onde predominam práticas de hierarquia e de mando extensivas aos operadores do direito.

Neste sentido, no caso das relações conjugais a prática cultural do "normal masculino" como a posição do "macho social" apresenta suas atitudes e relaçóes violentas como "atos corretivos" (MINAYO, 2005).

Geralmente quando narram seus comportamentos de violência os maridos (parceiros) costumam salientar que anterior a agressão buscam "avisar", "conversar "e posteriormente, se as vítimas, no caso suas mulheres (parceiras) não se submetem e obedecem ao comando, usam da força para agredi-las, considerando, portanto, que as atitudes advindas de suas mulheres, incluindo por extensão suas filhas, se encontram bem distantes da conduta ideal da qual se julgam guardióes, e, necessitam agir para garantir e controlar todas as atitudes e comportamentos delas (MINAYO, 2005).

Um discurso teórico importante a delinear se encontra no IV Plano Nacional contra a Violência Doméstica (BRASIL, 2010). Este plano consolidou na implantação de estratégias de intervenção no sentido de realizar prevenção a reincidência com intervençóes voltadas aos agressores. Quanto a trabalhos preventivos neste desfecho é real que esta área estratégica revolve como inovadora integrando seis medidas que tem a pretensão de reduzir o risco a revitimização/ reincidência pautado como crime de violência doméstica as atuais vítimas, ou na prevenção a vitimação em futuras relaçóes, sendo atualmente definida como uma prioridade em nível europeu. Neste sentido, o vasto arranjo para se implantar programas voltados à prevençáo da reincidência com agressores vem resultando em um conjunto de constataçóes tais como: insuficiência em trabalhar apenas com as vítimas; a intervenção contíguo aos agressores colabora para a alteração dos estereótipos e das crenças socialmente enraizadas, que, ajudam a vincular as condiçôes geradoras e a aceitação da violência doméstica; sendo expressivamente necessário trabalhar transversalmente as questóes que vinculem ao agressor a atribuição da responsabilidade. 
Concomitantemente as estratégias apontadas, alguns objetivos se atrelam às intervençóes propostas no IV Plano Nacional contra Violência Doméstica. Assim, foram esboçadas seus objetivos: Prevenção à reincidência; Disseminação e inovação de metodologias de controle penal, redução e alteração de comportamentos abusivos dos agressores, garantia da segurança as vítimas, a par da assunção da responsabilidade por parte do agressor e Promoção da eficácia dos mecanismos jurídico-penais.

Doravante, a Resolução do Conselho de Ministros n.o 102/2013 (BRASIL, 2013, p.7024), no V Plano Nacional contra Violência Doméstica e de Gênero vem de encontro com políticas de prevenção da reincidência da violência, dando evidência na assistência aos agressores quando esclarece que

Sendo a problemática da violência doméstica de extrema complexidade e implicando muitas vezes uma proximidade de risco entre vítimas diretas/ indiretas e agressores (as), a intervençáo junto de agressores(as) torna- -se uma prioridade, atendendo à necessidade de proteger as vítimas e prevenir a reincidência. Por outro lado, intervir junto de agressores (as) é um forte contributo para a interrupçáo de ciclos de reprodução de comportamentos violentos.

No tocante as formas de violência, bem como, a importância de realizar e estruturar legalmente medidas de prevenção e extinção da violência, salutar se torna entender como se concretiza na jurisprudência o conceito e formas de violência doméstica no contexto feminino, e assim, dar a condiçáo de se ponderar de que maneira se aplica a mesma lei para os homens. Diante disso, para buscar compreender como é aplicada a lei direcionada às mulheres alguns pontos serão delineados.

Conforme promulgado no artigo $5^{\circ}$ da Lei no 11.340/06 (BRASIL, 2006), configura-se violência doméstica e familiar contra a mulher

[...] qualquer ação ou omissão baseada no gênero que lhe cause morte, lesão, sofrimento físico, sexual ou psicológico e dano moral ou patrimonial:

I - no âmbito da unidade doméstica, compreendida como o espaço de convívio permanente de pessoas, com ou sem vínculo familiar, inclusive as esporadicamente agregadas;

II - no âmbito da família, compreendida como a comunidade formada por indivíduos que são ou se consideram aparentados, unidos por laços naturais, por afinidade ou por vontade expressa;

III - em qualquer relação íntima de afeto, na qual o agressor conviva ou tenha convivido com a ofendida, independentemente de coabitação. 
Parágrafo único. As relações pessoais enunciadas neste artigo independem de orientação sexual.

Art. $6^{\circ}$ A violência doméstica e familiar contra a mulher constitui uma das formas de violação dos direitos humanos.

Cabe referir que a Lei Maria da Penha foi norteada na Convenção Interamericana para Prevenir, Punir e Erradicar a Violência contra a Mulher (Convenção Belém do Pará), que expandiu a abrangência dos repertórios conceituais concernentes às múltiplas práticas da violência contra a mulher (BANDEIRA, 2009).

Nesta acepção, a violência Doméstica provoca diferentes consequências sobre a vítima, notadamente a saúde física e emocional, e, em inúmeras vezes sequelas de ordem psíquica.

De acordo com Day et al. (2003, p.16), dentre os quadros orgânicos, as sintomatologias resultam geralmente em lesóes, obesidade, distúrbio de ordem gastrointestinal, dor cronificada, morte entre outras sintomatologias.

Quanto ao comportamento das mulheres aos processos de agressão, reações femininas são bem singulares, ou seja, algumas mulheres resistem, outras se esquivam, outras tentam manter a paz quando submetidas às pretensóes do marido.

Day et al. (2003) enfatiza sobre os motivos mais alegados no que concerne à continuação dessas mulheres com o relacionamento conjugal, enfatizando que os motivos alegados para se fixarem na relação insana e abusiva se findam no medo da represália, perda do suporte financeiro, preocupação com os filhos, dependência emocional e financeira, assim como, esperança de que ocorrerá mudanças por parte do agressor.

Ainda cabe enfatizar que existem fatores que contribuem para a manutenção de uma relação conflitiva. Conforme relata Day et al. (2003, p.16),

[...] repetiçóes de modelo/parental violento, Vivências infantis de maus-tratos; negligência; rejeição; abandono e abuso sexual; Casamento como forma de fugir da situação familiar de origem, sendo o parceiro e relacionamento idealizados; Sintomas depressivos; Sentimento de responsabilidade pelo comportamento agressivo do companheiro, Ausência de uma rede de apoio eficaz no que se refere à moradia, escola, creche, saúde, atendimento policial e da justiça.

Para Silva et al. (2009), a diferença entre os tipos de violência, sendo elas de ordem física e psicológica, é que ambas estão envolvidas em atos de agressão, sendo que a primeira está atrelada a agressão corporal, enquanto a segunda forma de agressão decorre de palavras, gestos, olhares dirigidos, sem necessariamente 
ocorrer o contato físico. Destaca ainda a autora que a violência psicológica não atinge apenas a vítima diretamente, todavia, apreende a todos que presenciam ou coexistem com a situação de violência.

Assim, têm-se quatro formas mais comuns de violência intrafamiliar: física, psicológica, negligência e sexual. Segundo Day et al., (2003, p.10)

A violência física ocorre quando alguém causa ou tenta causar dano por meio de força física, de algum tipo de arma ou instrumento que possa causar lesôes internas, externas ou ambas.

A violência psicológica inclui toda ação ou omissão que causa ou visa a causar dano à autoestima, à identidade ou ao desenvolvimento da pessoa.

A negligência é a omissão de responsabilidade de um ou mais membros da família em relação a outro, sobretudo àqueles que precisam de ajuda por questóes de idade ou alguma condição física, permanente ou temporária.

A violência sexual é toda ação na qual uma pessoa, em situação de poder, obriga uma outra à realização de práticas sexuais, utilizando força física, influência psicológica ou uso de armas ou drogas.

Para a compreensão do tema e o desenvolvimento de atitudes vinculadas a violência doméstica envolvendo mulheres e nesta pesquisa os homens, necessário se faz apreender o significado de gênero, e posteriormente, a aglutinação de conhecimentos acerca da opressão gerada por este termo e os avanços atribuídos a violência doméstica.

Nesta lógica, o termo "gênero" é compreendido, segundo Araújo (2005, p.42)

[...] na sua acepção gramatical, designa indivíduos de sexos diferentes (masculino/feminino) ou coisas sexuadas, mas, na forma como vem sendo usado, nas últimas décadas, pela literatura feminista, adquiriu outras características: enfatiza a noção de cultura, situa-se na esfera social, diferentemente do conceito de "sexo", que se situa no plano biológico, e assume um caráter intrinsecamente relacional do feminino e do masculino.

O conceito de gênero passou a ser utilizado para a compreensão da complexidade das queixas, visto estar alicerçado enquanto construção social do masculino e feminino, assim como categoria de análise das relações envolvendo homens e mulheres (SANTOS; IZUMINO, [2005]).

No tocante as formas de opressão, estas são geradas a partir da questão de gênero, uma realidade objetiva que atinge um contingente de mulheres, permitindo a compreensão no âmbito sócio histórico cultural, mediante movimento intricado e colidente entre as vertentes de sociabilidade e 
individualidade, bem como, entre as relaçóes de gênero e a soma da vida social (SANTOS; OLIVEIRA, 2010).

Há, além disso, diferentes violências, as quais perpassam estas relaçóes, segundo Saffioti (2001, p.115)

Violência de gênero é o conceito mais amplo, abrangendo vítimas como mulheres, crianças e adolescentes de ambos os sexos. No exercício da função patriarcal, os homens detêm o poder de determinar a conduta das categorias sociais nomeadas, recebendo autorização ou, pelo menos, tolerância da sociedade para punir o que se lhes apresenta como desvio. Ainda que não haja nenhuma tentativa, por parte das vítimas potenciais, de trilhar caminhos diversos do prescrito pelas normas sociais, a execução do projeto de dominação-exploração da categoria social homens exige que sua capacidade de mando seja auxiliada pela violência. Com efeito, a ideologia de gênero é insuficiente para garantir a obediência das vítimas potenciais aos ditames do patriarca, tendo este necessidade de fazer uso da violência. Nada impede, embora seja inusitado, que uma mulher pratique violência física contra seu marido/companheiro/namorado. As mulheres como categoria social não têm, contudo, um projeto de dominação-exploração dos homens. E isto faz uma gigantesca diferença. Com relação a crianças e a adolescentes, também as mulheres podem desempenhar, por delegação, a função patriarcal.

Isto posto, é importante dirigir um olhar para questóes de violência contra os homens e compreender, à luz de teorias, a fuga destes na ocasião do oferecimento do tratamento psicológico no campo de suas angústias delatadas nas notificaçóes. O que se compreende neste sentido, é que a masculinidade perpassa por uma categoria relacional forte, contudo, provisória, visto que sua existência cultural vai depender do exercício do papel masculino, especificadamente o de provedor, "[...] o de pai e, sobretudo, o de marido que precisa assegurar a fidelidade da parceira no desafio com outros homens." (MINAYO, 2005, p.23).

Nesta acepção a concepção do masculino como sujeito da sexualidade e o feminino como objeto é valor de longa duração na cultura ocidental. De acordo com Minayo (2005, p.23-24)

$\mathrm{Na}$ visão arraigada no patriarcalismo, o masculino é ritualizado como o lugar da açấo, da decisão, da chefia da rede de relaçôes familiares e da paternidade como sinônimo de provimento material: é o "impensado" e o "naturalizado" dos valores tradicionais de gênero.

Diante do que se subscreveu, apesar das denúncias que deflagram as mulheres na inversáo de papel de vítima para a agressora, esta conduta coloca 
a masculinidade em ênfase como frágil e "afeminada", agredindo a construção interna do papel e identidade desenvolvida e torneada ao longo dos tempos.

Para tanto, verifica-se na maior parte das vezes denúncias de agressão originada de mulheres o que causa estranheza quando os homens delatam suas mulheres por agressóes de natureza doméstica. Assim, a voz feminina diante de inúmeras dilaceraçôes morais e físicas, não se calou, buscou iniciativas e medidas de proteção para descontruir o cenário de violência contra as mulheres. Neste sentido, deverá entâo o homem se mobilizar e fazer valer também seus gritos e tentar validar políticas públicas para proteção e intervenções neste universo atual em que estão sendo inferidos? Perguntas que não se calam, mas se silenciam na ocasião em que há a exposição de atos desta natureza envolvendo a população masculina. Vale salientar que nos casos de agressáo contra os homens a Lei Maria da Penha poderá ser aplicada por analogia para proteção dos homens.

De acordo com Sasse e Westin (2013) embora poucos há juízes que estão buscando "brechas" para aplicação da Lei Maria da Penha às avessas aos homens sujeitos a agressão. Um fato ocorrido em 2011 consolidou a aplicação de medida protetiva a um homem, ocasião em que sua ex-mulher de Campo Grande estava ameaçando-o.

Conforme Sasse e Westin (2013, p.8) para o deputado Gonzaga Patriota (PSB-PE),

[...] juízes como o de Campo Grande precisam se respaldar numa "versão masculina" da Lei Maria da Penha. Por isso, ele redigiu o Projeto de Lei 5.685/2009, que está em estudo na Câmara. — Não é desprezível o percentual de homens que sofreram ou sofrem calados, ao longo de vários anos, no recesso do lar, a violência psicológica, moral, patrimonial e corporal cometida por suas companheiras — argumenta.

No entanto, ressalta especialistas na Lei Maria da Penha quanto às interpretaçóes "alternativas", enfatizando ser um equívoco, visto ser a norma fulgente, pois a lei foi criada contra a violência doméstica e familiar e contra a mulher. Com relação aos homens enfatizam que estes sujeitos já estão protegidos de todos os tipos de violência pelo Código Penal (SASSE, et.al. 2013).

Observa-se, nesta direção, uma estagnação por parte do homem na busca pela própria legitimação e equidade de direitos. Entretanto, ao validar este direito dando vozes a violência masculina equivale a descontruir sua identidade de gênero.

Igualmente, nesta lógica, à denominação do homem machista para o entendimento da rigidez egoica até nos tempos atuais são aspectos importantes a ressaltar do artigo que engloba o tema relacionado a Laços insolentes entre o machismo e a violência. Para tanto, a concepção do masculino como súdito 
da sexualidade e, o feminino, por sua vez, como seu objeto é algo que vem de encontro com o valor de longa duração da cultura ocidental.

Nesta acepção, na visão arraigada do patriarcalismo, o masculino possui o rito da ação, da decisão, da chefia da rede de relaçóes familiares e, da paternidade, por sua vez, como sinônimo de provimento material, conforme exprime Minayo (2005, p.24)

[...] é o "impensado" e o "naturalizado" dos valores tradicionais de gênero. Da mesma forma e em consequência, o masculino é investido significativamente com a posição social (naturalizada) de agente do poder da violência, havendo, historicamente, uma relação direta entre as concepções vigentes de masculinidade e o exercício do domínio de pessoas, das guerras e das conquistas. O vocabulário militarista erudito e popular está recheado de expressôes machistas, não havendo como separar um de outro.

Do mesmo modo, a concepção do masculino está revestido pela posição social (naturalizada) do agente de poder da violência, seguindo dentro de um histórico, uma afinidade direta entre as percepçóes de masculinidade, bem como, no exercício do comando das pessoas, das guerras e das conquistas (MINAYO, 2005, p.24).

Assim sendo, o presente estudo visa problematizar a existência de denúncias por parte dos homens em situação de violência doméstica, assim como, dar ênfase, a negação frente às propostas de intervenções advindas no âmbito da saúde.

A realização deste estudo nasceu de demandas e mediaçóes solicitadas pelo Centro de Referência da Mulher do município de Araraquara ao Apoio a Saúde Mental, como forma de articular e promover possibilidades de atendimento Psicológico às vítimas do sexo masculino na ocasião da agressáo. O Apoio a Saúde Mental no exercício de suas atribuições buscou além de entender a análise das citadas notificaçóes, articular mediaçóes junto a um Centro de Referência ambulatorial em Saúde mental para promoção e intervençôes no âmbito da saúde.

\section{Percurso metodológico}

O percurso metodológico terá como embasamento a pesquisa qualitativa e dentro disso, o estudo documental.

A pesquisa documental segundo Silva et al. (2009) perpassa pelo cerne do método da investigação da realidade social, não acarreta uma única concepção filosófica de pesquisa, podendo ser empregada em abordagens tanto de natureza positivista, quanto de caráter compreensivo com enfoque mais crítico. Esta 
propriedade toma corpo de acordo com o referencial teórico que sustenta o pensamento do pesquisador, visto que náo somente os documentos escolhidos deverão responder às questôes da pesquisa, mas análise concomitantemente, exigindo desta forma do pesquisador uma capacidade reflexiva e criativa não só na compreensão do problema, mas nas relaçóes que consegue estabelecer.

Nesta perspectiva, a pesquisa documental consente investigar determinada problemática sem envolver uma interação imediatista, mas uma conduta de forma indireta, por meio de estudo de documentos produzidos pelo homem, revelando, nesta lógica, o seu modo de viver, de ser e compreender um fato social (SILVA et.al., 2009). Segundo o autor neste método de pesquisa

Depois de ser selecionada a amostra documental, segue-se o trabalho com a determinação de unidades de análises, a eleição das categorias e a organização do quadro de dados. (SILVA et.al., 2009, p.4560).

A análise de conteúdo decorre de relacionar a frequência da citaçáo de alguns temas, palavras ou ideias em um texto, com a finalidade de aferir o peso sugestivo que é atribuído a um determinado assunto pelo seu autor (CHIZZOTTI, 2006).

No tocante a análise de conteúdo envolvendo o material analisado, importante apreender acerca do nascimento do protocolo (fichas de notificaçáo), os dados elencados como critérios para o preenchimento.

O Ministério da Saúde (MS), verificando que as violências e os acidentes de transporte terrestre cumprem um grande peso social e econômico sobre o Sistema Único de Saúde/SUS, bem como, que as intervençôes pautadas na prevenção e promoção da saúde são escassas, implantou e assumiu, em 2001, a Política Nacional de Redução da Morbimortalidade por Acidentes e Violências. Para consolidar, o Ministério da Saúde realiza a publicação de um instrutivo publica para o Preenchimento da Ficha de Notificaçáo de Violência Interpessoal/ Autoprovocada. O objetivo das fichas é subsidiar os profissionais que atuam nas unidades/serviços notificadores a realizarem um preenchimento mais padronizado dessa ferramenta de coleta de dados (BRASIL, 2014, p.5).

Deste modo, cada ficha de notificação será analisada individualmente percorrendo dados como, Município, Unidade de Saúde, idade, sexo, ocupação, orientação do desejo sexual, escolaridade, estado civil, identidade de gênero, Motivação que norteou a violência (Sexismo, Homofobia/Lesbofobia/Transfobia, Racismo, Intolerância Religiosa, Xenofobia, Conflito Geracional, Situação de rua, deficiência, etc), tipos de violências, meios de agressão, se na ocasião ocorreu violência sexual, número dos envolvidos, vínculo/grau de parentesco com a pessoa atendida, sexo do provável autor da agressão, suspeita de uso de álcool, ciclo de vida do autor da agressão, assim como, os encaminhamentos realizados. 
Posteriormente a catalogação dos dados serão descritos em minúcias individualmente cada caso, desde a denúncia, até a realização de procedimentos interventivos no campo da saúde mental, através de um Centro de referência ambulatorial em saúde mental.

No que tange o perfil dos vitimados na ocasião da denúncia, os sujeitos se caracterizaram todos do sexo masculino, cinco se dizem heterossexuais e um homossexual.

As idades se configuraram da seguinte natureza, 51, 29, 26, 37, 28 e 24 anos. Os sujeitos vitimados se caracterizaram todos do sexo masculino, cuja orientaçáo sexual cinco são heterossexuais e um sujeito homossexual. A ocupação dos sujeitos era variante, ou seja, funcionário público municipal, advogado, professor, operador de máquina, empresário e em uma dessas fichas não havia registro. Quanto à escolaridade, dois concluíram o ensino médio, dois nível superior, um ensino fundamental e um sujeito não havia registro na ficha.

Com relação ao estado civil, três sujeitos eram casados, um não se aplicava aos dados da ficha, descrevendo como convivente, um solteiro e um sujeito náo havia descrição. O que se observou nas fichas de notificação é que as agressões constantes são de natureza psíquica/moral, e dentre essas apenas um caso se materializou em agressóes de ordem física com objeto perfuro-cortante. A motivação que norteou a violência foram dois caracterizados como conflito geracional, dois sexismo, um descrito como outros e um sem explicitaçóes na ficha.

O presente estudo foi realizado na cidade de Araraquara/SP, através da Apoiadora em Saúde Mental da Atenção Básica do Munícipio.

Cabe referir que as fichas de notificação/ investigação individual de Violência Interpessoal / Autoprovocada referentes aos homens foram preenchidas tanto em Unidade de pronto Atendimento (UPA), quanto em unidades básicas de saúde, mediante procura espontânea dos vitimados.

As unidades de saúde que realizaram a triagem dos vitimados foram Unidade de Pronto atendimento (central) e SESA (Serviço de atendimento especializado de Araraquara).

Os materiais utilizados para análise descritiva dos dados foram às fichas de notificação/investigação individual de Violência Interpessoal / Autoprovocada preenchidas nas Unidades de Saúde, na ocasiáo em que os vitimados realizaram a procura espontânea pelo atendimento.

Outro material utilizado para análise foi às respostas mediante contato por telefone aos vitimados como forma de convocá-los para triagem no Centro de Referência ambulatorial em saúde mental do adulto (CRASMA-A) e, posterior, a intervenção, traçar um Projeto Terapêutico singular para a demanda relacionada a violência e suas consequências. 
O procedimento de coleta de dados surgiu a partir das demandas advindas do Centro de referência da Mulher deste município, posto que naquele local os atendimentos são referenciados apenas no que se referem a mulheres vítimas de violência entre 18 a 59 anos de idade.

Esta Unidade que atende casos de violência relacionada apenas às mulheres, referenciou os Casos a Secretaria Municipal de Saúde por meio de ofício, propondo e discutindo junto com a Apoiadora da Saúde Mental diligências e procedimentos mandatórios de cunho interventivo.

\section{Resultados e discussão}

Apesar das denúncias altamente declaradas na rede de saúde na qual cada sujeito foi à procura de seus direitos, observou-se ainda que o silêncio tornou-se o objeto de defesa do agredido, sofismando em sobremaneira a exposiçáo de um masculino frágil, passivo e sombreado de uma corporeidade representada pelo gênero feminino.

No tocante a análise das notificaçóes, bem como, planejamento estratégico para intervençóes juntos aos vitimados, foi possível considerar que após o contato por telefone na tentativa de convocar os sujeitos para a realização do acolhimento/formação de vínculo e, posterior, engajamento em um projeto terapêutico, foi possível confirmar, através das ligaçôes, que os homens declararam que a denúncia se constituía táo somente nas notificaçóes sem objetivo algum de tratamento, deixando "evidente" que a conduta se consolidava apenas na exposição da mulher, bem como, inferência de sentimentos de temor nas mesmas, deixando fulgente que sua angustias após o evento não necessitavam ser explicitadas e intervindas em qualquer tipo de ação para promoção de saúde, ou seja, verbalizaçóes que hipoteticamente se manifestavam como forma de fugaesquiva no que tange a exposição.

Outra questão importante na denúncia no qual estavam envolvidos mãe e filho foi à caracterização nas informaçôes adicionais no qual consta o uso do cartão de crédito sem o consentimento do filho, distinguindo, neste contexto, para o vitimado como meio de agressão a extorsão.

Um ponto importante nas relaçóes de ofensiva foi a resultante de um caso envolvendo auto-agressão, sequenciada de tentativa de suicídio. Todavia várias tentativas para localização do vitimado pelo Centro de Referência Ambulatorial em Saúde mental foram realizadas, e, diante disso, o caso foi encaminhado para a Estratégia de Saúde da Família para que o Núcleo de Apoio a Saúde da Família (NASF) realize assim os procedimentos na busca ativa do vitimado e, desta maneira, possam realizar intervençóes efetivas a conduta delineada na Notificação. 
Quanto aos meios de agressão, os casos se concluíam em: um caso de extorsão, quatro de ameaça e apenas um caso envolvendo auto-agressão. Assim, cabe aludir que em nenhum dos casos foi declarado violência de natureza sexual.

A predominância dos tipos de violência no estudo foram: cinco casos catalogados à violência Psicológica/Moral e um caso apontado como agressão física autoprovocada. Os meios de agressão se classificavam em cinco casos envolvendo ameaça e um caso com objeto perfuro-cortante. Neste sentido, um caso curioso que resultou em denúncia foi à extorsão como meio de agressão, ou seja, a mãe era o agente agressor, cujo objeto que disparou a ação do vitimado foi o uso do cartão de crédito sem consentimento. Quanto ao vínculo/grau de parentesco um caso envolvia a própria pessoa, uma ex-companheira (esposa), uma mãe, uma ex-namorada e (dois sujeitos) envolvidos destacados como amigos/ conhecidos.

O sexo dos prováveis agressores se predominava em três do sexo feminino e três do sexo masculino.

As denúncias classificadas como ameaça foram dois casos que envolviam ex-namorada e companheira; e um abarcando amigos/conhecidos e, um outro, sem especificaçóes de vínculo. $\mathrm{O}$ ciclo de vida de todos os autores está classificado como adultos e nenhum deles estava motivado pelo uso abusivo de álcool ou outras Substâncias Psicoativas.

Os encaminhamentos determinados como necessários na ficha de notificação compulsória se desdobraram para a Delegacia de Defesa da Mulher, ocasião em que nenhum dos vitimados prosseguiu com a conduta de peticionar o Boletim de Ocorrência, deixando apenas registrado seus relatos na ocasião em que procuraram a Unidade de Saúde. A negação frente as proposta de atendimento a esta demanda é algo expressivamente notório, levando a conjecturas de que os homens entendem que a exposição de sua figura neste cenário os levará a subversão da identidade de gênero.

Doravante, conclui-se que se incorpora o silêncio nesta relaçáo ambivalente (homem e mulher), quando se firma a denúncia no sentido de atemorização da agressora, fixando, dentro deste entrave, um mecanismo mantenedor do papel masculino, uma vez que, assumir para o outro (profissional) a fragilidade diante do feminino, é declarar e perder uma identidade construída socialmente em delongo tempo.

Desta maneira, há de se firmar que a agressão de qualquer natureza envolvendo diferentes gêneros é algo a se refletir, sobretudo pensando em propor metodologias de intervenção para o controle destas práticas, ou (quiçá) saná-las, visto que tais comportamentos é uma produção recursiva de atos ilícitos que fatalmente induzem de algum modo à destruiçáo do outro e das relaçóes como um todo. 


\section{Considerações finais}

Considerando que a violência doméstica é um problema de natureza social e que validam geralmente as mulheres, o presente estudo busca demonstrar que o homem também é alvo da dinâmica aludida. Por isto, é necessário repensar o panorama legal para unificar os direitos para a participaçáo do homem. Há de se considerar que os avanços se consolidaram pelo fato da mulher suprimir suas angústias, medo e atemorizaçóes para a efetivação e consolidação de Direitos. Observa-se que em estudos semelhantes há interesse da aplicação da Lei Maria da Penha a população masculina, entretanto, observa-se que os homens não compartilham da personalidade proativa da mulher quando se trata de validar o próprio universo feminino, mesmo que neste sentido evidencie as suas faces e corporeidade sobrevindas de ofensivas e destruiçóes advindas da violência.

As diversas formas de se praticar a violência é algo evidente, nomeadamente, as que se particularizam em agressóes físicas e psicológicas, podendo, neste cenário, serem protagonistas, mulheres, crianças, adolescentes e idosos de ambos os sexos. Neste sentido, a partir da deflagração de violência perpetrada contra os homens consolidar a Violência de Gênero em seu conceito mais amplo conforme promulgado no V Plano Nacional de Prevenção e combate a violência Doméstica e de Gênero (2014-2017), é garantir a permeabilidade da Lei na aplicação para ambos os sexos, por se tratar de violação dos direitos humanos, e, nesta direção, fortalecer políticas de prevenção contra a violência em diversos segmentos e atores, visto que este tema não se esgota em tempo real, pois não há apenas o sujeito mulher as margens de um cenário abusivo, há também, nesta vertente, um sujeito homem com todas as suas reservas patriarcais.

Ante o exposto, há de se refletir sobre o tema e produzir, além disso, políticas que fortaleçam o gênero masculino a exercer, com a mesma coragem, o desejo da equidade de direitos no cerne da violência doméstica. Não obstante, os homens deveráo se despir da supremacia masculina, da austeridade e machismo para produzir mecanismos de enfrentamento e validação jurisprudencial no combate as diversas formas de violência no universo masculino.

Nesta acepção, construir equipamento que acolham as demandas advindas do gênero masculino é algo igualmente a se refletir, visto que em pesquisas que abarcam a mulher, a criação de programas romperam, confrontaram e subverteram disposições enraizadas na banalização à violência doméstica difundidas no imaginário social, reafirmando, dentro disso, que a implantação deste órgão na assistência as mulheres admitiu papel expressivo na mudança de paradigmas, produzindo novos referenciais simbólicos, que perpassam pelo crivo do respeito, autonomia e inclusão (CÔRTES, 2012).

No tocante a resolubilidade do problema de pesquisa acerca de quais motivos influenciaram os homens a não darem continuidade às notificaçôes compulsórias 
de violência praticada contra eles, assim como, a recusa frente à participação dos mesmos no que concerne a intervençôes no âmbito psicológico, foi possível observar a prevalência marcante da sociedade patriarcal a qual é contingente e mantenedora do status quo, garantindo que a identidade de gênero não será anulada, significando o silêncio o objeto de defesa do agredido.

As fichas de notificaçôes compulsórias é um questionário abrangente e estruturado. Contudo, apesar da abrangência de informaçóes, o que tornou intrincado para a explanaçáo dos dados foi à falta de especificaçóes dos profissionais que realizaram a coleta das informaçóes na ocasiáo da denúncia, deixando incertos itens objetivos e de relevância, evidenciando, desta maneira, a necessidade da capacitação e qualificação permanente de profissionais. Observase assim, a expressiva necessidade da escuta qualificada dos profissionais frente à demanda do vitimado para a compreensão fidedigna da violência instalada, e esta ação, necessariamente, deverá acontecer mediante intervençóes/acolhimento no campo da psicologia.

Outro ponto de difícil acesso foi à busca ativa pelos vitimados para a participação de intervençôes no campo da saúde mental, especialmente, por assumirem a denúncia. Contudo, denegam as intervençóes, sustentando e firmando suas identidades nos padróes refratários do masculino inalcançável, desafiador e indestrutível, o que salienta o quanto que estudos que se debruçam acerca da violência doméstica contra homens são necessários, sobretudo, pensando em se articular estratégias preventivas e interventivas. 


\section{REFERÊNCIAS}

ARAÚJO, M. F. Diferença e igualdade nas relaçóes de gênero: revisitando o debate. Psicologia Clínica, Rio de Janeiro, v.17, n.2, p.41-52, 2005. Disponível em: <http://www. scielo.br/pdf/pc/v17n2/v17n2a04.pdf>. Acesso em: 14 ago. 2015.

BANDEIRA, L. Três décadas de resistência feminista contra o sexismo e a violência feminina no Brasil: 1976 a 2006. Sociedade e Estado, Brasília, v. 24, n. 2, p. 401-438, maio/ago. 2009. Disponível em: <http://www.scielo.br/pdf/se/v24n2/04.pdf>. Acesso em: 27 ago. 2015.

BRASIL. Ministério da Saúde. Secretaria de Vigilância em Saúde. Instrutivo para preenchimento da ficha de notificaçáo de violência interpessoal/autoprovocada. Brasília, 2014. Disponível em: <http:/www.dive.sc.gov.br/conteudos/agravos/publicacoes/ Instrutivo\%20VIVA\%20SINAN\%205.0.pdf>. Acesso em: 20 ago. 2015.

Resolução do Conselho de Ministros n.o 102/2013. Diário da República, Brasília, n.253, p.7017-7035, 31 dez. 2013. Disponível em: <https://dre.pt/application/dir/ pdf1sdip/2013/12/25300/0701707035.pdf>. Acesso em: 25 ago. 2015.

Resolução do Conselho de Ministros n.o 100/2010. Diário da República, Brasília, n.243, p.5763-5773, 17 dez. 2010. Disponível em: <https://dre.pt/application/dir/ pdf1sdip/2010/12/24300/0576305773.pdf>. Acesso em: 25 ago. 2015.

Lei $\mathrm{n}^{\circ} 11.340$, de 7 de agosto de 2006. Cria mecanismos para coibir a violência doméstica e familiar contra a mulher, nos termos do $\$ 8$ o do art. 226 da Constituiçáo Federal, da Convenção sobre a Eliminação de Todas as Formas de Discriminação contra as Mulheres e da Convenção Interamericana para Prevenir, Punir e Erradicar a Violência contra a Mulher; dispóe sobre a criação dos Juizados de Violência Doméstica e Familiar contra a Mulher; altera o Código de Processo Penal, o Código Penal e a Lei de Execução Penal; e dá outras providências. Diário Oficial [da] República Federativa do Brasil, Brasília, 08 ago. 2006. Disponível em <http://www.planalto.gov.br/ccivil_03/_ato2004-2006/2006/lei/ 111340.htm>. Acesso em: 16 jul. 2015.

BLAY, E. A. Violência contra a mulher e políticas públicas. Estudos Avançados, São Paulo, v.17, n.49, p.91-98, 2003. Disponível em: <http://www.scielo.br/pdf/ea/v17n49/18398. pdf>. Acesso em: 01 dez. 2015.

CHIZZOTTI, A. Pesquisa qualitativa em ciências humanas e sociais. Petrópolis, RJ: Vozes, 2006.

CÔRTES, G. R. Violência doméstica: centro de referência da mulher "Heleieth Saffioti". Estudos Sociológicos, Araraquara, v.17, n.32, p.149-168, 2012. Disponível em: <http:// seer.fclar.unesp.br/estudos/article/viewFile/4932/4121>. Acesso em: 20 ago. 2015.

DAY, P. V. et al. Violência doméstica e suas diferentes manifestaçóes. Revista de Psiquiatria do Rio Grande do Sul, Rio Grande do Sul, v.25, sup.1, p.9-21, 2003. Disponível em: <http://www.scielo.br/scielo.php?script=sci_arttext\&pid=S0101-81082003000400003>. Acesso em: 15 jul. 2015. 
MINAYO, M. C S. Laços perigosos entre machismo e violência. Ciência \& Saúde Coletiva, Rio de Janeiro, v.10, n.1, p. 18-34, 2005. Disponível em: <http://www.scielo.br/pdf/csc/ v10n1/a03cv10n1>. Acesso em: 25 jul. 2015.

SAFFIOTI, H. I. B. Contribuições feministas para o estudo da violência de gênero. Cadernos Pagu, v.16, p.115-136, 2001. Disponível em: <http://www.scielo.br/pdf/cpa/n16/ n16a07.pdf>. Acesso em: 19 ago. 2015.

SANTOS, C. M.; IZUMINO, W. P. Violência contra as mulheres e violência de gênero: notas sobre estudos feministas no Brasil. [2005]. Disponível em: <http://www.nevusp.org/ downloads/down083.pdf>. Acesso em: 14 ago. 2015.

SANTOS, S. M. M.; OLIVEIRA, L. Igualdade nas relaçóes de gênero na sociedade do capital: limites, contradiçóes e avanços. Revista Katál, Florianópolis, v.13, n.1, p.11-19, jan./jun. 2010. Disponível em: <http://www.scielo.br/pdf/rk/v13n1/02.pdf>. Acesso em: 21 ago. 2015.

SASSE, C.; WESTIN, R. O inferno das mulheres. Jornal do Senado, Brasília, ano 19, n. 3.9064, jul. 2013. Disponível em: <http://www12.senado.gov.br/jornal/edicoes/ especiais/2013/07/04/projeto-preve-lei-no-estilo-maria-da-penha-para-proteger-homemagredido-por-mulher>. Acesso em: 20 jul. 2015.

SILVA, L. R. C. et al. Pesquisa documental: alternativa investigativa na formação docente. In: CONGRESSO NACIONAL DE EDUCAÇÃO, 9. ; ENCONTRO SUL BRASILEIRO DE PSICOPEDAGOGIA, 3., 2009, Curitiba. Anais... Curitiba: PUPR, 2009. p.1-13. Disponível em: <http://www.pucpr.br/eventos/educere/educere2009/anais/pdf/3124_1712. pdf $>$. Acesso em: 14 ago. 2015. 
Resumo

Violência doméstica contra o homem: de agressor a agredido

O presente estudo visa elucidar a existência de denúncias por parte dos homens em situação de violência doméstica, assim como, dar ênfase a negaçáo frente às propostas de intervençóes advindas no campo da saúde a partir de notificaçôes compulsórias. Além da análise destas notificaçôes propóe averiguar a presença ou não de políticas públicas voltadas ao acolhimento desta demanda, e de que maneira os vitimados se articularam para a legitimação de direitos no cerne da Violência Doméstica. O percurso metodológico se embasou na pesquisa qualitativa e, dentro disso, o estudo documental. Apesar das denúncias altamente declaradas na rede de saúde na qual cada sujeito foi à procura de seus direitos, observa-se ainda que o silêncio torna-se objeto de defesa do agredido. Deste modo, é preciso a permeabilidade da Lei Maria da Penha para ambos os sexos, e, concomitantemente, fortalecer e construir políticas de prevençáo contra a violência em diversos segmentos e atores, sobretudo, por este tema não se esgotar em tempo real uma vez que náo há apenas a mulher as margens de um cenário abusivo, mas; igualmente, o homem com suas reservas patriarcais dando ênfase neste recorte.

Palavras-chave: Relação conjugal. Violência doméstica. Notificação compulsória.

\section{Abstract}

\section{Domestic violence against men: the offender being assaulted}

This study aims to elucidate the existence of complaints by men who have suffered domestic violence, as well as to emphasize the denial of any interventions for health care after the violence is notified. In addition to the analysis of these notifications, it is also proposed to determine the presence or absence of public actions to embrace this need, and how the victims acted to have their legitimate rights to be helped against domestic violence. The methodological approach was based in qualitative research and, within that, cases study. Despite the highly rates of complaints to the health sector in which each subject looked for their rights, it is observed that the silence is the only defense for the attacked ones. Thus, the use of Maria da Penha Law is necessary for both sexes, and concomitantly strengthen and build policies to prevent violence in various sectors and subjects, especially because this theme does not run out in real time because not only are women suffering in abusive scenarios, but also are men with their patriarchal reserves emphasizing this occurrence.

Keywords: Marital relationship. Domestic violence. Compulsory notification. 
